\title{
Spectral characteristics of the hippocampal LFP during contextual fear conditioning
}

\author{
Características espectrais da atividade elétrica hipocampal durante \\ o medo condicionado ao contexto
}

\author{
Birajara Soares Machadoํㅡ, Ana Carolina Bione Kunicki², Edgard Morya ${ }^{3}$, Koichi Sameshima²
}

\begin{abstract}
Objective: The hippocampus has an important role in the acquisition and recall of aversive memories. The objective of this study was to investigate the relationship among hippocampal rhythms. Methods: Microeletrodes arrays were implanted in the hippocampus of Wistar rats. The animals were trained and tested in a contextual fear conditioning task. The training consisted in applying shocks in the legs. The memory test was performed 1 day (recent memory) or 18 days (remote memory) after training. We proposed a measure based on the FFT power spectrum, denominated "delta-theta ratio", to characterize the different behaviors (active exploration and freezing) and the memories types. Results: The delta-theta ratio was able to distinguish recent and remote memories. In this study, the ratio for the 18-day group was smaller than for the 1-day group. Moreover, this measure was useful to distinguish the different behavior states - active exploration and freezing. Conclusions: The results suggest delta-theta oscillations could reflect the demands on information processing during recent and remote memory recalls.
\end{abstract}

Keywords: Hippocampus; Memory; Fear/physiology; Amnesia retrograde

\section{RESUMO}

Objetivo: 0 hipocampo tem um importante papel na aquisição e evocação das memórias aversivas. Pretendeu-se, neste trabalho, investigar a dinâmica entre os ritmos hipocampais durante a evocação das memórias aversivas recente e remota. Métodos: Foram implantadas matrizes de microeletrodos em ratos Wistar. Os animais foram treinados e testados numa tarefa de condicionamento contextual de medo. 0 treino consistiu em aplicações de choques nas patas. 0 teste de memória foi realizado 1 dia (memória recente) ou 18 dias (memória remota) após o treino. Nesse trabalho, foi proposta uma medida baseada no espectro de potências, denominada "razão delta-theta", para caracterização dos diferentes comportamentos observados (vigília exploratória e congelamento) e tipos de memórias. Resultados: A razão delta-theta mostrou-se capaz de distinguir os grupos testados para as memórias recente e remota. Neste caso, observou-se, para o grupo testado 18 dias após, um valor menor do que para o grupo testado 1 dia após. Além disso, essa medida mostrou-se útil para distinguir os diferentes estados comportamentais. Conclusões: Os resultados sugerem que a dinâmica entre os ritmos delta e theta pode refletir o processamento da informação durante a evocação das memórias recente e remota.

Descritores: Hipocampo; Memória; Medo/fisiologia; Amnésia retrógrada

\section{INTRODUCTION}

The hippocampus has an important role in the acquisition of aversive memories. However, these memories are not stored permanently in the hippocampus. Hippocampal lesions, in humans and animals, produce serious deficits in recent memory, but not in remote memory ${ }^{(1-3)}$. The current hypothesis suggests that the hippocampus is dynamically involved in a gradual process of reorganization and stabilization of memories in the neocortex $^{(4-6)}$.

Evidence from experiments carried out by Bontempi et al. ${ }^{(7)}$ and Frakland et al. ${ }^{(8)}$ shows that several cortical regions such as the anterior cingulate cortex and pre and infralimbic cortices are involved in the processing of aversive memories, consistent with the proposal that remote memories are stored in distributed cortical networks. Numerous studies have investigated the

Study carried out at the Medical School, Universidade de São Paulo - USP, São Paulo (SP), Brazil.

1 Instituto do Cérebro - InCe, Hospital Israelita Albert Einstein - HIAE, São Paulo (SP), Brazil.

${ }^{2}$ Faculdade de Medicina, Universidade de São Paulo - USP, São Paulo (SP), Brazil.

${ }^{3}$ Associação Alberto Santos Dumont para Apoio à Pesquisa - São Paulo (SP), Brazil.

Corresponding author: Birajara Soares Machado - Avenida Albert Einstein, 627/701 - Morumbi - Zip code: 05652-000 - São Paulo (SP), Brazil - Phone: (55 11) 2151-7354 - E-mail: birasm@gmail.com

Received on: Sep 1, 2011 - Accepted on: Apr 24, 2012

Conflicts of interest: none. 
cellular and molecular basis involved in the recall and storage of recent and remote memories ${ }^{(9-12)}$. However, the electrophysiological mechanisms involved in the time course of the cortico-hippocampal circuit are not yet well known.

In rats, an excellent paradigm for the behavioral study of recent and remote memories is contextual fear conditioning ${ }^{(1,2)}$. This paradigm involves placing the animal in a given context (pre-exposure) and applying electric shocks in the legs (training). The memory test is performed with two separate groups of rats trained with 5 shocks in the legs and tested 1 day (recent memory) or 18 days (remote memory) after training. Using this paradigm, we selected two behavioral states: active exploration, in pre-exposure, and freezing, a characteristic behavior observed in tests of memory.

\section{METHODS}

We used 12 male Wistar rats from the School of Medicine, Universidade de São Paulo (USP), weighing approximately $300 \mathrm{~g}$ at the beginning of the experiment. The animals were kept under controlled temperature $\left(23 \pm 2^{\circ} \mathrm{C}\right)$ and 12 hour/12 hour light/dark cycle, in which the lights were turned on at $7 \mathrm{am}$. Food and water were provided ad libitum. All procedures adopted were in accordance with the guidelines of the FMUSP Ethics Committee for Animal Research (CAPPesq 0948/09).

The animals were weighed and anesthetized with ketamine hydrochloride $(100 \mathrm{mg} / \mathrm{kg})$ and xylazine $(4 \mathrm{mg} / \mathrm{kg})$ after previous induction with $5 \%$ halothane. The level of sedation was maintained with supplemental doses of $20 \%$ of the initial dose of ketamine per hour, or whenever the animal presented sensitivity to pain. After trichotomy and antisepsis of the surgical field, the rats were placed in a stereotaxic device (model 900, David Kopf Instruments, Tujunga, California) and a longitudinal skin incision in the midline of the skull was performed. A high speed dental drill was used to perform the craniotomy, opening three holes in which stainless steel microscrews were inserted. The microscrews fixed the implant in the skull with cyanoacrylate glue and served as contact points for the ground wire reference. The microelectrode arrays were implanted by stereotactic technique in the hippocampal CA1 region, with the center at the following anteroposterior (AP), mediolateral (ML) and dorsoventral (DV) coordinates from bregma: AP -3.60, ML 2.60, and DV 2.10mm.

One week after the implant surgery, a recording was performed using a local field potential acquisition equipment (Multichannel Acquisition Processor, Plexon Inc., Dallas). The signals were pre-amplified (1000x), filtered through a $0.3 \mathrm{~Hz}$ high-pass filter and a $400 \mathrm{~Hz}$ low-pass filter, and digitized by means of a (National Instruments, Austin) 64-channel board at an acquisition frequency of $2 \mathrm{kHz}$.

The rats were divided into two groups (G1 and G18, six rats per group). All animals underwent microelectrode implantation to record hippocampal electrical activity and were euthanized after the test - group G1 one day after training, and group G18 18 days after training. All animals were trained and tested in a contextual fear conditioning task. For this purpose, we used a conditioning box $\left(26 \times 21 \times 27.5 \mathrm{~cm}^{3}\right)$, with black walls and transparent acrylic cover. The floor consisted of a metal grid (with edges of $16.4 \mathrm{~mm}$ in diameter and equally spaced every $1.2 \mathrm{~cm}$ ) connected to a discontinuous shock source. The conditioning box was placed in a Faraday cage $\left(89.5 \times 79 \times 54 \mathrm{~cm}^{3}\right)$. On top of this cage we set up an infrared CCD video camera to record the animal's behavior during the task.

The animals were habituated to the experimenter and to the environment, which was different from the conditioning place, with 5-minute sessions per day for 7 consecutive days. The training and test sessions were conducted during the light phase of the circadian cycle of the rat. In the first day (pre-exposure to the context), the animal was placed in the conditioning box for 5 minutes. In the second day (training), the animal was placed in the conditioning box and, after 2 minutes, received electric shocks in the legs. Each shock was of $0.7 \mathrm{~mA}$ intensity and 2 seconds in duration. A total of 5 interleaved shocks were applied for 1 minute. The animals were reintroduced into the conditioning box for recall tests to asses recent (group G1) or remote (group G18) memories. The freezing time was recorded by the experimenter observing the animal's behavior via the CCD video camera.

Behavior analysis was performed based on visual inspection of the video of the animals, frame by frame. The animal's behavioral state was classified as quiet awake, active exploration and freezing. The animal was considered in active exploration state when it presented intense exploratory locomotor activity, or in freezing state when it presented total absence of movements except those associated with respiratory movements. In this context, the quiet awake is behaviorally equivalent to freezing. Figure 1 shows the freezing rates in trained groups and control group (animals which did not receive shock in the legs). 


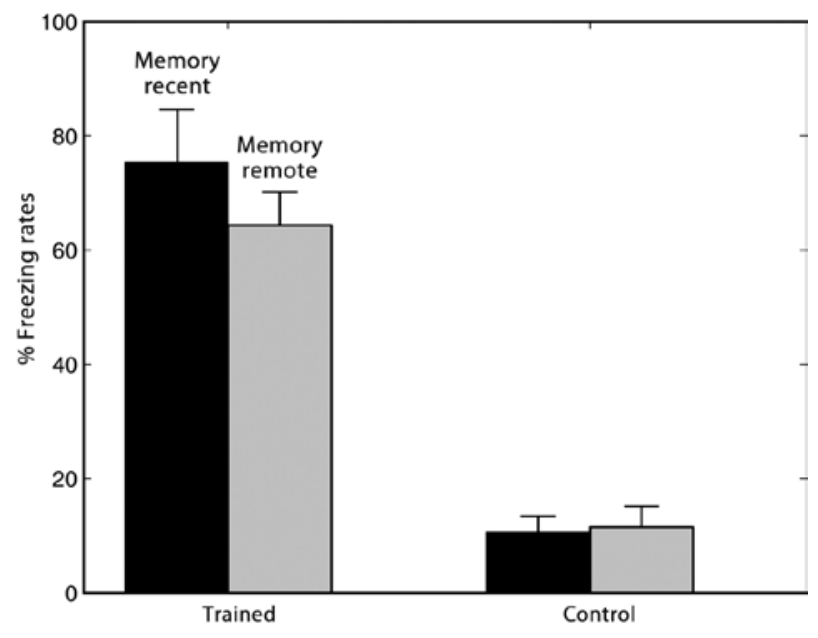

Figure 1. Freezing rates of trained and control animals. The trained groups are subdivided into those who underwent the test one day after training (recent memory) and 18 days after training (remote memory)

Perfusion was performed through the left ventricle with paraformaldehyde in $0.1 \mathrm{M}$ buffer. Before opening the thoracic cavity, the animals were anesthetized with ketamine hydrochloride $(350 \mathrm{mg} / \mathrm{kg})$ and xylazine $(4 \mathrm{mg} / \mathrm{kg})$. After perfusion, the brain was removed and frozen at $-80^{\circ} \mathrm{C}$ for subsequent tissue section and staining. Nissl staining using cresyl violet dye was conducted to identify the position of the electrodes.

We selected segments (duration of 2 seconds) of the electrophysiological recordings in the three behaviors of interest: active exploration and freezing, besides the quiet awake. The first is related to the signals recorded before the animal was subjected to applications of shock in the legs. The freezing behavior was recorded in order to compare brain rhythms in the recall of recent and remote memories. Figure 2 illustrates examples of the three states of interest. Quiet awake records were obtained from the control group.

To study the electrophysiological mechanisms involved in fear conditioning, we proposed a measure based on power spectrum ratios, considering the contributions of slow oscillations, in the other words

where

$$
\rho_{\delta \theta}=\overline{\mathrm{E}}_{\delta} / \overline{\mathrm{E}}_{\theta} \text {, }
$$

$$
\overline{\mathrm{E}}_{\omega}=\frac{\int_{v_{\mathrm{s}}}^{v_{\theta}}|\tilde{f}(v)|^{2} d v}{\int_{v_{\mathrm{s}}}^{v_{\theta}} d v}
$$

and $f(v)$ is the Fourier transform of the signal $f(t)$. Therefore, $\overline{\mathrm{E}}_{\omega}$ can be interpreted as the normalized power spectrum of a specific electrophysiological signal $f(t)$ in a certain range of frequencies $\omega=\left[v_{s}, v_{e}\right]$. The $\rho_{\delta \theta}$ measure is defined by the ratio between the average

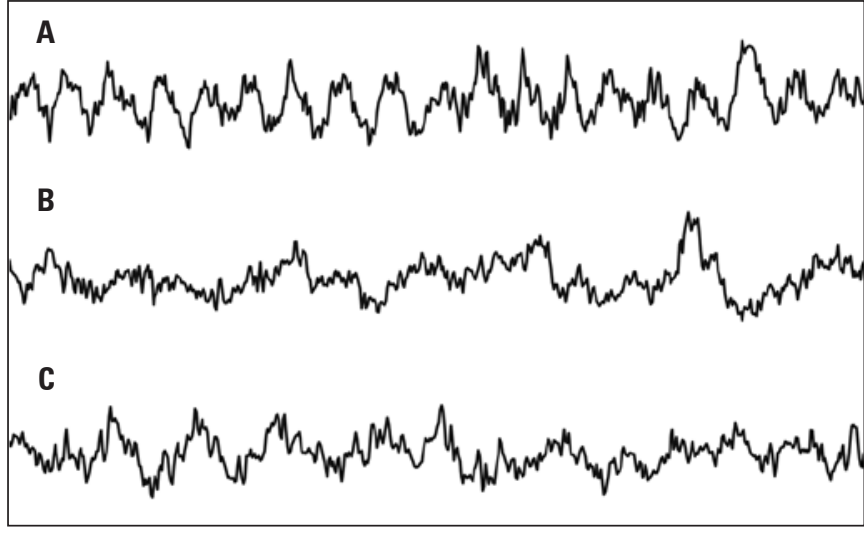

Figure 2. Two-second segments of hippocampal electrical activity in behaviora states: (A) active exploration, (B) freezing 1 day after training and; (C) freezing 18 days after training. All signals range of $\pm 0.5 \mathrm{mV}$

energies of delta $(0.5$ and $4 \mathrm{~Hz})$ and theta $(4$ and $10 \mathrm{~Hz})$ rhythms, as shown in figure 3 . The estimator of the power spectrum used in this study was proposed by Welch ${ }^{(13)}$. This procedure consists in dividing the time series data into overlapping segments. For each segment, the power spectrum is obtained, and the average of the estimates is calculated.

The nonparametric statistical tests for comparison of the delta-theta ratio were the Wilcoxon signed rank test ( $W$-test), for paired comparisons, and the MannWhitney test ( $U$-test), for comparison of independent samples. Due to sample size (six animals per group) it was decided not to conduct a normality test. The $\rho_{\delta \theta}$ values comparison for active exploration G1 and G18 and the two control groups was performed by one-way ANOVA ( $F$-test). The level of significance for all statistical tests was 0.05 .

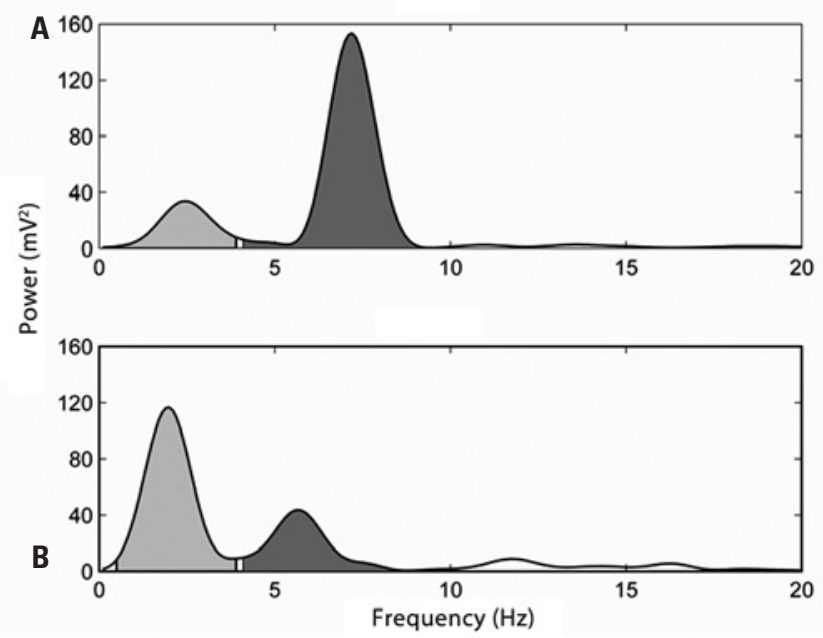

Figure 3. Characteristic power spectra in behavioral states: $(A)$ active exploration, and (B) freezing. Delta-theta ratios are 0.415 and 3.748 , respectively 


\section{RESULTS}

The delta-theta ratio allowed the characterization of recent and remote memories $(p<0.005 ; U$-test $)$. In this case, the ratio for the tested animals after 18 days (3.231 \pm 0.970$)$ was lower when compared with the tested group after 1 day $(6.778 \pm 1.316)$, featuring a slower activity during recent memory recall. Moreover, this measure proved to be useful to distinguish different behavioral states - active exploration $(0.314 \pm 0.099, \mathrm{G} 1$ group; $0.370 \pm 0.208$, G18 group) and freezing ( $p<0.05$, for G1 e G18 groups; $W$-test). More specifically, the delta-theta ratio of animals in active exploration is lower when compared to animals in freezing. A significant difference was observed $(p<0.005, U$-test $)$ in $\rho_{\delta \theta}$-values test with the respective control groups $(0.309 \pm 0.033$, 1 day after; $0.341 \pm 0.050,18$ day after) from the quiet awake. Finally, an ANOVA test was applied in the $\rho_{\delta \theta}$-values from the behavior states active exploration and quiet awake. No significant difference was not observed $(p=0.241 ; F$-test). Figure 4 summarizes the main results.

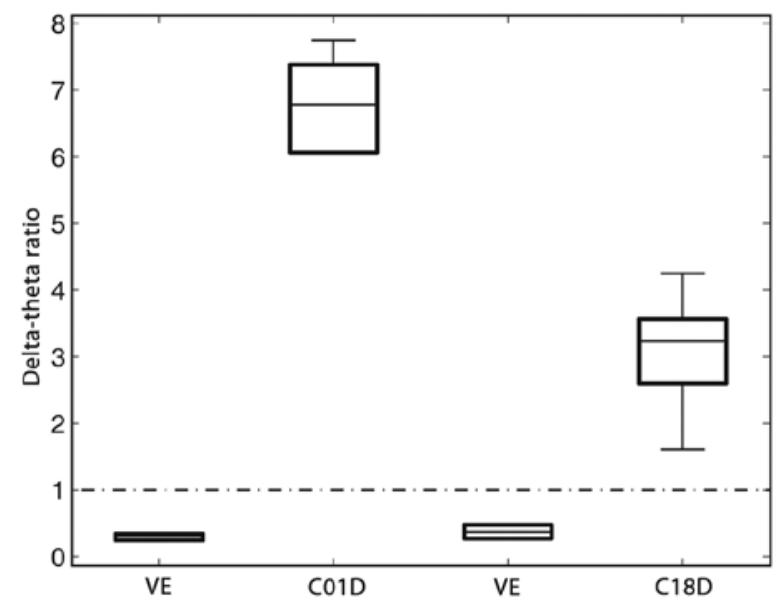

Figure 4. Box diagram of the delta-theta ratio during active exploration (VE) and 1 day freezing (CO1D) and 18 days (C18D) after training

\section{DISCUSSION}

In the behavioral paradigm studied, the freezing level was used as an indication of the memory retention rate. There was a decrease in the freezing rate over time depending on the type of memory recalled. Similar results were described by Rudy and Wright-Hardesty(14). These authors showed that there is a direct relationship between the freezing level and the interval between training and testing of memory retention. Additionally, the delta-theta ratio also showed that the characteristic electrophysiological pattern of the hippocampus during freezing also decreased.
It is well established in the literature that, during active exploration, the predominant brain electrical activity in the hippocampus is the theta rhythm ${ }^{(15-17)}$. Our results corroborate these findings and also show, during freezing reaction, a significant increase in delta rhythm in the typical brain activity when compared to the hippocampal theta rhythm.

A model to explain the oscillatory brain dynamics was proposed by Lakatos et al. ${ }^{(18)}$. These researchers suggest that there is a hierarchical organization in brain electrical activity, in which the amplitude of each oscillatory frequency is modulated by the phase of a low frequency oscillation. Lakatos et al. ${ }^{(19)}$ showed earlier that the phase of these oscillatory activities control the excitability of cortical neuronal populations and thus may influence sensory stimuli processing. Further studies on the dynamics of the interaction among brain rhythms are needed, since this may be an important mechanism to facilitate memory consolidation processes. In this study, we found that the dynamics between delta and theta waves changes depending on the type of memory recalled.

Frankland et al. ${ }^{(8)}$ reported that immediate early genes Fos and Zif-268 are strongly activated in the hippocampus after recent memory recall, but not after remote memory recall. The opposite was observed in the medial prefrontal cortex, which revealed a significant increase in the expression of these genes after remote memory recall, but not after recent memory recall. These results indicate that the recall of different types of memory is mediated by different mechanisms in different brain regions.

The delta-theta ratio proved to be a useful measure in the characterization of behavioral states. Additionally, it differentiated groups of animals in freezing state during recent and remote memory recalls. Thus, the relationship between delta and theta rhythms may be an important parameter to be considered in the study of processes related to learning and memory.

Another relevant issue is the significant increase of the contribution of delta rhythm accompanied by a decrease in theta rhythm during recent memory recall. This may indicate a slowing of hippocampal activity. Knowing that the hippocampus has an important role in the acquisition of recent memory, but not of remote memory, it is suggested that the hippocampus coordinates the distribution of information to the neocortex over time. It is possible that the slowing of the hippocampus facilitates communication in the cortico-hippocampal circuitry, since the neocortex has a slower activity ${ }^{(20,21)}$. It is proposed that the communication between the areas of the brain occurs by 
means of synchronization events, and that these events would be facilitated by resonant activities. Finally, the subsequent restoration of hippocampal theta activity can be interpreted as a decrease of the hippocampal participation in the memory processes.

\section{CONCLUSION}

The results suggest that the relationship between delta and theta rhythms may reflect the information processing during recent and remote memory recalls.

\section{ACKNOWLEDGEMENTS}

We thank the Permanent Forum of University-Industry Relations and the Foundation for Research Support of São Paulo (FAPESP).

\section{REFERENCES}

1. Kim JJ, Fanselow MS. Modality-specific retrograde amnesia of fear. Science. 1992;256(5057):675-7.

2. Anagnostaras SG, Maren S, Fanselow MS. Temporally graded retrograde amnesia of contextual fear after hippocampal damage in rats: within-subjects examination. J Neurosci. 1999;19(3):1106-14.

3. Manns JR, Hopkins RO, Squire LR. Semantic memory and the human hippocampus. Neuron. 2003;38(1):127-33.

4. Zola-Morgan SM, Squire LR. The primate hippocampal formation: evidence for a time-limited role in memory storage. Science. 1990;250(4978):288-90.

5. Squire LR, Alvarez P. Retrograde amnesia and memory consolidation: a neurobiological perspective. Curr Opin Neurobiol. 1995;5(2):169-77.

6. Knowlton BJ, Fanselow MS. The hippocampus, consolidation and on-line memory. Curr Opin Neurobiol. 1998;8(2):293-6

7. Bontempi B, Laurent-Demir C, Destrade C, Jaffard R. Time-dependent reorganization of brain circuitry underlying long-term memory storage. Nature. 1999;400(6745):671-5.
8. Frankland PW, Bontempi B, Talton LE, Kaczmarek L, Silva AJ. The involvement of the anterior cingulate cortex in remote contextual fear memory. Science. 2004;304(5672):881-3.

9. Routtenberg A, Cantallops I, Zaffuto S, Serrano P, Namgung U. Enhanced learning after genetic overexpression of a brain growth protein. Proc Natl Acad Sci USA. 2000;97(13):7657-62.

10. Maviel T, Durkin TP, Menzaghi F, Bontempi B. Sites of neocortical reorganization critical for remote spatial memory. Science.2004;305(5680):96-9.

11. Frankland PW, Bontempi B. The organization of recent and remote memories. Nat Rev Neurosci. 2005;6(2):119-30.

12. Takehara-Nishiuchi K, Nakao K, Kawahara S, Matsuki N, Kirino Y. Systems consolidation requires postlearning activation of NMDA receptors in the medial prefrontal cortex in trace eyeblink conditioning. J Neurosci. 2006; 26(19):5049-58.

13. Welch PD. The use of fast fourier transform for the estimation of power spectra: a method based on time averaging over short, modified periodograms. IEEE Trans Audio Electroacoust. 1967;15(2):70-3.

14. Rudy JW, Wright-Hardesty K. The temporal dynamics of retention of a context memory: something is missing. Learn Mem. 2005;12(2):172-7.

15. Vanderwolf $\mathrm{CH}$. Hippocampal electrical activity and voluntary movement in the rat. Electroencephalogr Clin Neurophysiol. 1969;26(4):407-18.

16. Gavrilov VV, Wiener SI, Berthoz A. Enhanced hippocampal theta EEG during whole body rotations in awake restrained rats. Neurosci Lett. 1995; 197(3):239-41.

17. Slawinska $U$, Kasicki $S$. The frequency of rat's hippocampal theta rhythm is related to the speed of locomotion. Brain Res. 1998;796(1-2):327-31.

18. Lakatos P, Shah AS, Knuth KH, Ulbert I, Karmos G, Schroeder CE. An oscillatory hierarchy controlling neuronal excitability and stimulus processing in the auditory cortex. J Neurophysiol. 2005;94(3):1904-11.

19. Lakatos P, Szilágyi N, Pincze Z, Rajkai C, Ulbert I, Karmos G. Attention and arousal related modulation of spontaneous gamma-activity in the auditory cortex of the cat. Brain Res Cogn Brain Res. 2004:19(1):1-9.

20. Sirota A, Csicsvari J, Buhl D, Buzsáki G. Communication between neocortex and hippocampus during sleep in rodents. Proc Natl Acad Sci U S A. 2003; 100(4):2065-9.

21. Mölle M, Yeshenko O, Marshall L, Sara SJ, Born J. Hippocampal sharp waveripples linked to slow oscillations in rat slow-wave sleep. J Neurophysiol. 2006;96(1):62-70. 